Kinetic and kinematic analysis of gait during transport of the wheeled backpack in schoolchildren from 7 to 10 years of age

\title{
Anólise cinética e cinemática da marcha durante o transporte da mochila com rodas em escolares de 7 a 10 anos de idade
}

\author{
Pablo de Almeida'; Luiz Augusto da Silval; Carlos Ricardo Maneck Malfatti² \\ ${ }^{1}$ Colegiado de Educação Física - Faculdade Guariracá - FAG. Guarapuava, PR - Brasil. \\ ${ }^{2}$ Departamento de Educação física - Universidade Estadual do Centro-Oeste - UNICENTRO. Guarapuava, PR - Brasil. \\ Endereço para Correspondência: \\ Luiz Augusto da Silva \\ Rua XV de Novembro, 7050 - Centro \\ 85010-000 - Guarapuava - PR [Brasil] \\ lasilva7@hotmail.com
}

\begin{abstract}
Introduction: The overweight of school backpacks results in an increase of mechanical load in the locomotive apparatus of the students during the locomotion. Objective: Analyze and compare kinetic and kinematic temporal/spatial variables during gait and transport of backpacks with wheels $(10 \%$ body weight of load) in schoolchildren aged 7 to 10 years. Methods: Ten healthy children (7.8 \pm 1.6 years) participate in two experimental conditions, first condition involved the gait in the plane, and the second condition the backpack transport provided with wheels in the plane (10\% body weight) occurred. Results: Soil reaction forces in force platform did not show any differences between the conditions. The similarities indicate that wheeled backpacks do not require time changes or application of forces to perform the task when compared to the unladen gait in the plane. The kinematics of the ankle, knee and pelvis remained unchanged. Conclusion: The use of $10 \%$ BW of load in the backpack during transport was not influenced gait.

Keywords: Gait; Children; Posture; Health Promotion.
\end{abstract}

\section{Resumo}

Introdução: A sobrecarga em mochilas escolares pode resultar em aumento de carga mecânica sobre o aparelho locomotuvo de estudantes durante a marcha. Objetivo: Analisar e comparar as variáveis temporais/espaciais cinéticas e cinemáticas durante a marcha e o transporte de mochilas com rodas $(10 \%$ peso corporal (PC)) em escolares de 7 a 10 anos. Métodos: Dez crianças, saudáveis (7.8 \pm 1.6 anos) participaram de duas condições experimentais, sendo a primeira envolvendo a marcha, enquanto a segunda ocorreu o transporte de mochila provida de rodas, $10 \%$ PC. Resultados: As forças de reação do solo não apresentaram diferenças entre as duas condições. Porém, mostrou-se que mochilas com rodas não alteram aplicação de forças para execução da tarefa quando comparadas a marcha sem carga na locomoção. A cinemática do tornozelo, do joelho e da pelve permaneceram inalteradas. Conclusão: $\mathrm{O}$ uso de rodas na mochila para o transporte de carga de $10 \%$ PC não influenciou no padrão de marcha aplicado durante a marcha no plano.

Descritores: Marcha, Crianças, Postura; Promoção da Saúde. 


\section{Introduction}

Physical-posture problems can affect children and adolescents in the growth phase and are a risk factor for spinal dysfunctions, as they tend to be difficult to treat or even to be irreversible in adulthood. ${ }^{1}$ Studies have reported that $80 \%$ of the population in industrialized countries will experience episodes of acute back pain at some point in their life, ${ }^{2}$ which may be related to postural changes triggered in the adolescence and pre-adolescence phases..$^{3-5}$

Changes in posture induced by cargo transport have attracted attention from several researchers due to the search for a better understanding of the risk factors for the development of problems associated with loading loads. Despite the important contribution of these studies, the large variety of backpacks used by schoolchildren indicates a lack of consensus on the "ideal" form of transportation. ${ }^{6}$

The overweight of school backpacks results in an increase of mechanical load in the locomotive apparatus of the students during the locomotion, as shown by several studies. ${ }^{78}$ Low back pain may also be directly related to the strategies employed by the musculoskeletal system when adapting differently to the weights transported. Thus, backpacks equipped with wheels for transport have an apparent lower physical demand when compared to other models and forms of loading by means of backpacks usually attached to the trunk (eg, backpack).

Changes in posture induced by cargo transport have called attention to a better understanding of the risk factors for the development of problems associated with loading loads. ${ }^{9}$ In general, the transport strategy and the types of backpack used for transport have been studied. ${ }^{10}$

School backpacks with wheels have been widely used by schoolchildren in an attempt to minimize the effect of transported weight. Although there are favorable arguments for the use of this type of cargo transport, by dissipating the cargo closer to the ground than a double-loop backpack, no studies are known that have deter- mined the body adjustments required during the task (eg lateral rotation of the trunk). The physical demand and the adjustment strategies imposed in this type of cargo transport have not yet been quantified and can help in the understanding of the adaptations of the neuromuscular system. Some studies have revealed that symmetrical methods of loading backpacks have lower physical demands than asymmetric methods. ${ }^{9-11}$

The lateral inclination of the trunk made during the transport of backpacks can cause negative effects on the corporal structures and lead to the appearance of discomfort, pain and disability. Such changes require bodily adjustments that may alter interactions between lower limbs (eg soil reaction force (FRS)) and expose young people to greater risk of injury. Thus, the objective of the present study is to determine the effects of the use of the school backpack with wheels on kinematic and kinetic variables during the transport of loads (school materials) in children.

\section{Methodological procedures}

Ten healthy children $(7.8 \pm 1.6$ years $)$ were selected to participate in the study, being primary school students of Public and / or Private Colleges located in the city of Curitiba - PR. The invitation was made directly to the parents of students who were observed within the described age group and who used the backpack with wheels to transport school materials. All the selected participants signed a free and informed consent form that was previously approved by the Ethics Committee in Research with Human Beings of the University of Parana (UNIPAR) with protocol 18459/2009. Subjects with a BMI above 19 kg.m2, significant postural deviations, chronic or acute low back pain or other orthopedic problems that could limit their ability to carry weights were excluded from the study.

Experimental protocol

On the day of the experiment the subjects underwent an evaluation of the weight of the corporal mass, since the loads to be transported 
corresponded to $10 \%$ of the corporal weight. The subjects were instructed to walk in a straight line through the space previously calibrated without the use of the backpack, which was described as the moment without load. At a later stage, the students carried the backpack with $10 \%$ of the body weight corresponding to each subject.

A familiarization period was followed, which consisted of walking in a $9.0 \mathrm{~m} \times 7.0 \mathrm{~m}$ flat space, in which participants had the opportunity to walk freely. Six optical capture cameras (MX-13, Vicon) were positioned, sampling at a frequency of $100 \mathrm{~Hz}$, positioned so that at least one mark was captured by at least two cameras in order to allow the reconstruction of the march in three dimensions (3D) ${ }_{1}^{12}$ as shown in Figure 1. The synchronization of the collected images was performed automatically by the equipment (Peak Motus 9, Vicon, USA). Measurement errors in this type of analysis have been described as minimum $(<1 \mathrm{~mm})$ according to the equipment manufacturer.

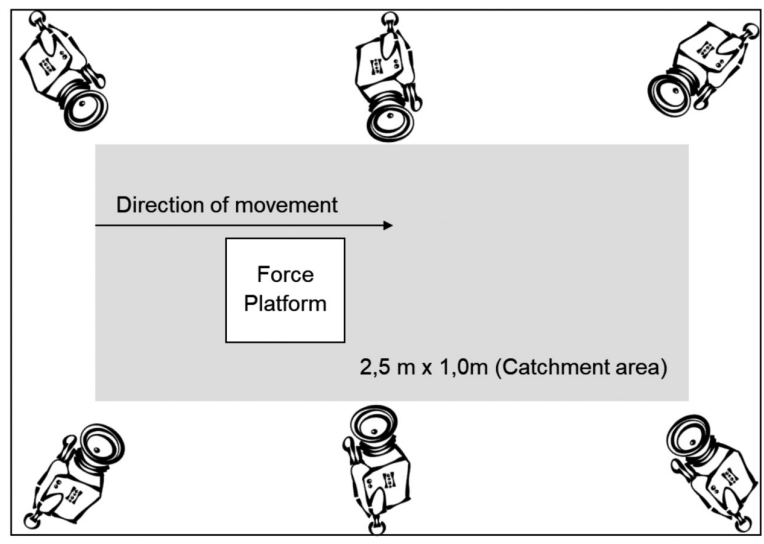

Figure 1: Organization of the collection area $^{12}$

Source: Delgado.

The gait speed was monitored and the values of the experimental conditions were compared with the values found for the unladen gait. The unloaded gait $(0 \%)$ was the first to be quantified while the experimental conditions were performed in random order. Under the experimental conditions, the loads were fixed to the structure of a wheeled backpack that had its cargo compartment removed. In this way, the metallic structure, handle and the wheels, did not prevent the points of the corporal markers during the transport.

A set of ten gait cycles was captured in each condition and subsequently the cycles that had clear definition of the points were grouped. The grouped mean was calculated after each of the movements were normalized as a function of the gait cycle, ie, the first contact of the right heel on the ground corresponded to the first instant $(0 \%)$ while the second contact of the same segment was defined as the last instant (100\%). Calculations were made through spline-like routines.

\section{Kinematic analysis}

Prior to the start of each evaluation, the gait area was calibrated using a reference object as determined by the manufacturer (Peak Motus 9, Vicon, USA). An area of $2.5 \mathrm{~m}$ in length, 1.0 $\mathrm{m}$ in width and $1.8 \mathrm{~m}$ in height was defined for recording movements. Each participant received a collant and black pants that were sufficiently tight to the body, and a set of reflective markers (diameter $1 \mathrm{~cm}$ ) was fixed to the skin (some points) and the clothing where possible, bilaterally (exception point 7 - thigh), according to the model. ${ }^{13}$ The marks were fixed by the same evaluator in the following anatomical points: antero-superior iliac spines (1), femoral trochanter head (2), lateral femoral epicondyle (3), lateral malleolus of the tibia (4), calcaneus fifth phalangeal metatarsus of the foot (6), greater perimeter of the right thigh in the anterior medial region (7). These sets of markers were used to define the following body segments: pelvis (1), thigh (2 and 3$)$, leg (3 and 4), and foot (4,5 and 6). Number 7 was used to determine the thigh and right leg segment plan, respectively, according to the procedures described by Persch. ${ }^{14}$

\section{Kinetic analysis}

The soil reaction forces were quantified by means of a force platform (AMTI, model OR6 
- 7, USA) fixed to the ground and covered by a rubber mat that did not allow participants to identify their location. The soil reaction forces were captured synchronously to the kinematic data. Participants were instructed to walk straight at self-selected speed and experimenters guided the exit site in order to match the touch of the right heel with the ground on the center of the platform. Participants were also walked. Table 1 shows the kinetic variables evaluated in the study.

\section{Standardization of data}

After filtering the data were normalized as a function of time and expressed by relative and absolute values, besides representing the percentage of the gait cycle from a specific software that uses spline functions. Each dataset was expressed so that all could contain 100 points. After normalization, the pooled mean of three trials were calculated and used to represent the performance of each subject during the two experimental conditions (in the plane and with a backpack).

\section{Statistical analysis}

All variables were analyzed through descriptive statistics by mean and standard deviation. The Levene and Shapiro-Wilks tests were performed and confirmed the normality and homogeneity of the data. Student's $t$ test for dependent samples was performed on all variables. The level of significance was set at $p \leq 0.05$. Statistical analysis of the data was done using statistical software Statistica, version 5.5.

\section{Results}

\section{Kinetic analysis}

Table 1 shows the kinetic variables for the differences between the gait conditions in the plane and loading of the backpack with wheels.
The comparison of the experimental conditions of the first peak of force (FZ1) showed similarity $(p=0.331)$ between walking with $(1.16 \pm 0.24)$ and without backpack $(1.18 \pm 0.14)$. The results of this study showed higher magnitudes of the ground reaction forces during the gait in the plane $(0.72 \pm 0.08)$ when compared to the transport of the backpack with wheels $(0.64 \pm 0.16)$ for the mean support force (Fz2). However, no differences were found between the experimental conditions $(p=0.241)$.

It can be observed that the second peak of ground reaction (FZ3) during the walking (1.06 $\pm 0.05)$ was similar $(\mathrm{p}=0.41)$ than that presented during transport of the backpack $(1.09 \pm 0.15)$. The time of the first peak of force ( $\Delta \mathrm{t}$ Fz1), mean support time ( $\Delta \mathrm{t} \mathrm{Fz2})$, second peak time ( $\Delta \mathrm{t}$ Fz3), total support time $(\Delta \mathrm{t})$ and total cycle time $(\Delta \mathrm{t}$ cycle) also did not differ between experimental conditions $(p>0.05)$.

Table 1: Kinetic variables (mean \pm standard deviation) between gait conditions in the plane (without backpack) and backpack transport with wheels (with backpac k).

\begin{tabular}{cccc}
\hline Variable & $\begin{array}{c}\text { Without } \\
\text { backpack }\end{array}$ & $\begin{array}{c}\text { With } \\
\text { backpack }\end{array}$ & $P$ \\
\hline Fz1 (BW) & $1.18 \pm 0.14$ & $1.16 \pm 0.24$ & 0.331 \\
\hline Fz2 $(B W)$ & $0.72 \pm 0.08$ & $0.64 \pm 0.16$ & 0.241 \\
\hline Fz3 $(B W)$ & $1.06 \pm 0.05$ & $1.09 \pm 0.15$ & 0.409 \\
\hline$\Delta t$ Fz1 (s) & $0.14 \pm 0.03$ & $0.15 \pm 0.04$ & 0.458 \\
\hline$\Delta t$ Fz2 (s) & $0.30 \pm 0.12$ & $0.31 \pm 0.09$ & 0.695 \\
\hline$\Delta t$ Fz3 (s) & $0.42 \pm 0.07$ & $0.45 \pm 0.08$ & 0.361 \\
\hline$\Delta t(s)$ & $0.55 \pm 0.08$ & $0.58 \pm 0.13$ & 0.561 \\
\hline$G C(B W / s)$ & $8.75 \pm 2.28$ & $8.41 \pm 3.27$ & 0.329 \\
\hline
\end{tabular}

Fz1 (BW) - Initial peak force normalized by Body Weight; Fz2 (BW) - Mean support force normalized by body weight; Fz3 (BW) - End peak force normalized by body weight; $\Delta t$ Fz1 - Time of the first force peak; $\Delta \mathrm{t}$ Fz2 - Mean support time; $\Delta \mathrm{t}$ Fz3 - Time of the second force peak; $\Delta t$ - Total time of support; GC $(\mathrm{f} / \mathrm{t}$ ) - Growth Gradient of the initial peak.

Source: The autors.

The growth gradient (GC) found in the present study for gait without backpack $(8.75 \pm$ $2.28)$ and with backpack and $(8.41 \pm 3.27)$ were similar $(\mathrm{p}=0.329)$. The spatial and temporal 
variables of the kinetic parameters did not differ, regardless of the condition (with and without backpack).

\section{Kinematic Variables}

Table 2 shows the kinematic variables for the differences between the walking conditions in the plane and loading of the wheeled backpack. During gait in the plane, the length of the stride was similar to that found during transportation with backpacks with wheels ( $p$ $=0.084)$. The differences were small between the experimental conditions and did not exceed $3.7 \%$ in relation to the gait in the plane (without load). The height of the foot relative to the ground did not differ between the conditions. In fact, when comparing the conditions can be observed similar and the average variations did not oscillate more than $0.1 \mathrm{~cm}$.

The ankle plantiflexion peak (PF) was not influenced by the transport of the backpack, since no changes in the kinematic characteristics were detected between the experimental conditions. Temporal characteristics also reveal similarity between tasks. It is noted that the bending peaks occurred at close instants in both conditions (63\% and 65\%, respectively). During the gait the peak of the ankle flexion (PF) in the plane was $15.2^{\circ}$ and for the backpack transport with wheels $17.2^{\circ}(p=0.387)$.

The ankle dorsiflexion (PD) peaks occurred at $12.06^{\circ}$ for the cycle of gait in the plane (without backpack), and at $10.62^{\circ}$ in the transport of the backpack with wheels, no significant differences were found $(p=0.580)$. It was also observed that dorsiflexion peaks occurred at similar times between the conditions $(42 \%$ and $44 \%$ of the cycle, respectively).

Figure 2 shows the angular displacement of the ankle, thigh, knee and pelvis observed during gait in the plane. The first bending peak (PO) of the knee was $18.8^{\circ}$ and occurred at $16 \%$ of the gait cycle. The mean of the second peak (SO) of knee flexion was $64.9^{\circ}$ and occurred at $74 \%$ of gait cycle. During transportation of the
Table 02: Kinematic variables (mean \pm standard deviation) between gait conditions in the plane (without backpack) and backpack transport with wheels (with backpack).

\begin{tabular}{cccc}
\hline Variable & $\begin{array}{c}\text { Without } \\
\text { backpack }\end{array}$ & $\begin{array}{c}\text { With } \\
\text { backpack }\end{array}$ & $\mathrm{p}$ \\
\hline $\begin{array}{c}\text { Travel speed } \\
\text { (m/s) }\end{array}$ & $1.26 \pm 0.16$ & $1.20 \pm 0.20$ & 0.342 \\
\hline $\begin{array}{c}\text { Total cycle } \\
\text { time (s) }\end{array}$ & $0.889 \pm 0.112$ & $0.907 \pm 0.158$ & 0.577 \\
\hline $\begin{array}{c}\text { Cadence (min/ } \\
\text { total time) }\end{array}$ & $67.49 \pm 8.70$ & $66.15 \pm 8.78$ & 0.610 \\
\hline $\begin{array}{c}\text { Length of } \\
\text { stride (m) }\end{array}$ & $1.11 \pm 0.06$ & $1.07 \pm 0.09$ & 0.084 \\
\hline $\begin{array}{c}\text { Foot height } \\
\text { (m) }\end{array}$ & $0.024 \pm 0.005$ & $0.023 \pm 0.006$ & 0.405 \\
\hline $\begin{array}{c}\text { Peak plantar } \\
\text { flexion of } \\
\text { the ankle } \\
\text { (degrees) }\end{array}$ & $15.20 \pm 8.74$ & $17.23 \pm 6.13$ & 0.387 \\
\hline $\begin{array}{c}\text { Peak } \\
\text { dorsiflexion } \\
\text { of the ankle } \\
\text { (degrees) }\end{array}$ & $12.06 \pm 6.68$ & $10.62 \pm 5.15$ & 0.580 \\
\hline $\begin{array}{c}\text { Knee } \\
\text { flexion peak } \\
\text { - First wave } \\
\text { (degrees) }\end{array}$ & $18.80 \pm 4.84$ & $20.74 \pm 6.12$ & 0.712 \\
\hline $\begin{array}{c}\text { Knee flexion } \\
\text { peak - Second } \\
\text { wave } \\
\text { (degrees) }\end{array}$ & $64.89 \pm 9.08$ & $62.21 \pm 6.14$ & 0.366 \\
\hline $\begin{array}{c}\text { Thigh } \\
\text { of pelvic } \\
\text { rotation } \\
\text { (degrees) }\end{array}$ & $12.62 \pm 5.96$ & $12.64 \pm 3.96$ & 0.257 \\
\hline $\begin{array}{c}\text { Peak (degrees) } \\
\text { Angular peak }\end{array}$ & $16.79 \pm 3.81$ & $17.48 \pm 3.88$ & 0.668 \\
\hline
\end{tabular}

Source: The autors.

backpack the first peak was $20.7^{\circ}$ and occurred at $15 \%$ of the gait cycle, while the second peak was $62.2^{\circ}$ and occurred at $74 \%$ of the gait cycle. No differences were found in the magnitude and time at which the first and second knee flexion peak occurred between experimental conditions.

The values found for the angular displacement of the thigh segment were $16.8^{\circ}$ dur- 
ing the extension (PE) for the gait in the plane and $17.5^{\circ}$ during the loading of the backpack. There were no significant differences between the conditions ( $p=0.668)$. The analysis of the moments that the maximum extension of the thigh occurred also did not differ $(54 \%$ in both conditions).

The gait in the plane presented a pelvic rotation peak (PRP) of $12.6^{\circ}$, which occurred at $52 \%$ of the gait cycle in the displacement. No differences were found between gait compared to the condition involving the transportation of a wheeled backpack, in which the pelvic rotation peak was $12.6^{\circ}$ and occurred at $56 \%$ of the gait cycle.

\section{Discussion}

The kinetic variables were chosen in order to represent the reaction forces and to characterize the parameters of interaction of the feet with the ground during the transport of the school backpack with wheels and during the march in the plane.

It can be inferred that the loading of the wheeled bag demands a pattern similar to the unladen gait and does not require important changes at this stage, which justifies the similarity of the FZ2 FRS in both conditions. Hong et al. (2005) examined children carrying dualloop backpacks and found that loads of $15 \%$ of
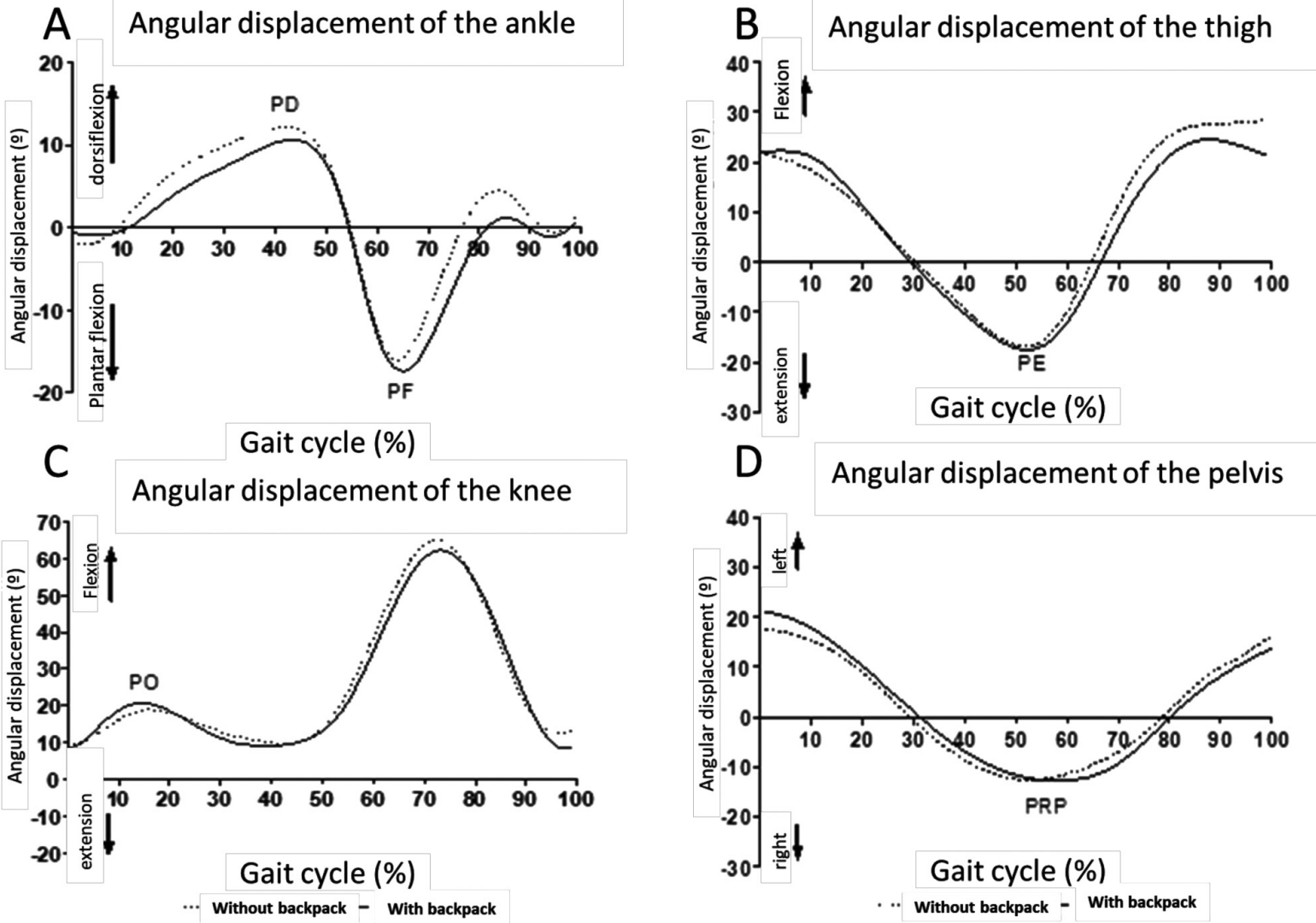

Figure 2: Angle displacement of the (A) right ankle joint, (B) thigh (c) right knee, and (D) Pelvis during loading of school backpack with wheels (full line) and plane (dotted line). PD: Peak dorsiflexion of the right ankle joint; PF: peak of the plantar flexion of the right ankle joint. PO: First wave of flexion of the right knee joint; SO: Second wave of flexion of the right knee joint; PE: Peak moment of extension of the thigh. PRP: right pelvic rotation peak. 
body mass (transported in double-loop dorsal backpacks) induced increases in the duration of the dual support phase. The temporal similarity between the total support time between the experimental conditions indicates that the transport of backpacks with wheels does not influence the time of support and consequently does not require of the subjects the need to implement larger times to carry out the task of carrying backpacks with wheels when compared to non-plane gait.

The values reported by Estrázulas ${ }^{15}$ for the group of children during gait in the plane were similar with the present study, in both conditions. Peneireiro, ${ }^{11}$ analyzed the transport of backpacks loaded laterally with a pelvic belt and with a simple handle with implementations of loads corresponding to $12 \%$ in relation to the BW of each subject and found higher magnitudes (1.37 \pm 0.11 and $1.35 \pm 0.09$, respectively) of than those obtained in the present study. What can be associated with forces that are transmitted directly to the ground when the loads are transported through backpacks with wheels and less overload on the locomotor apparatus. Therefore, the similarity between the conditions (backpack and plane) point to very similar demand.

Orantes-Gonzalez ${ }^{16}$ compared the gait of 53 children using the backpack, backpacking and backpacking, and found that the use of the backpack is similar to free-riding (without the use of backpacks), in kinetic and kinematic aspects.

The similarity found in the FRS parameters between all variables in relation to the results reported by Estrázulas et al. ${ }^{15}$ and Hong et al. ${ }^{17}$ reflect the gait characteristics of healthy individuals for the participants in this study. The analysis of the magnitudes and temporal aspects of the soil reaction forces demonstrated a stable pattern of the actions performed during the loading of the wheeled backpack. These findings do not point to the need to use differentiated strategies for the transportation of backpacks with wheels when compared to the gait in the plane. It is necessary to point out that the duration of these events varies according to the gait speed, which was controlled in both experimental conditions, thus, speed variations can not explain the similarities found between the conditions.

Regarding the kinematic variables, they were chosen in order to represent the most important actions of the gait cycle in the plane and during transportation of the school backpack with wheels. The results of the comparisons of this study revealed that both groups (with and without backpack) presented similar gait patterns, which means similarity between the conditions, that is, during the tests the children were able to adapt their locomotor patterns according to the demand through the transport of wheeled backpacks when traveling in the plane without loading.

During the transport of wheeled backpacks, the upper limb remains extended to hold the upper rod of the backpack, and tends to reduce the actions generated by the ankle around the pelvis, since the relative attachment of the segment to retract the backpack and the load. Thus, from a theoretical point of view, the use of backpacks with wheels may require greater joint amplitude of the ankle as a compensatory way to preserve gait actions by the greater impulse needed to raise the pelvis. However, the $10 \%$ load did not appear to have an expressive effect on the ankle, which remained relatively unchanged. In fact, corroborating kinematics, the kinetic variables do not point to greater momentum in the propulsive phase of the movement.

The speed of the march is directly related to the cadence and the length of the pitch. The results of the study by Himmann et al..$^{18}$ showed that the frequency of steps remains unchanged for males, independent of age. Although the subjects walked in the plane carrying a load equivalent to $10 \%$ BW in a backpack with wheels, a similar pattern was found when compared to the march in the plane (without backpack). This similarity suggests that there is no need for increase in cadence or step length. 
In the study by Mann et $\mathrm{al}^{19}$, the loading of the load was carried out by the body, while in the present study the task allowed the weight of the load to be transmitted directly to the ground. Thus, the demand for the task of transporting loads with wheeled backpacks was not sufficient to cause changes in the length of the stride. In fact, although it involves the transport of a load, the use of wheels in the backpack seems to produce no differences in the length of the stride relative to the plane. The results demonstrate a tendency to decrease the length of the stride ( $p=$ 0.08), suggesting a possible effect.

The children participating in this study behaved in exactly the same way as the angular displacement patterns of the knee. Thus, similarity of angular displacement of the knee between gait with and without backpack with wheels points to a demand that does not require adjustments. Probably, the weight transfer must have been discharged directly to the ground, due to its location (backpack) and in this way allowed the maintenance of the gait characteristics in the plane.

The findings of the thigh and pelvis movement of the present study represent similarities to the patterns found in the literature. During the initial balance the thigh goes through an extension phase around $15^{\circ}$. The final position around $25^{\circ}$ of the flexed thigh is maintained within a five degree variation during the final balance. The thigh and pelvis are closely related during the gait cycle, and if pelvic tilt occurs, the amplitude of the thigh segment can be modified during the cycle, and may also influence the positioning of the foot.

The behavior of the hip angle is characterized by the maximum extension in the touch of the opposite foot and by a maximum flexion in the terminal balance that occur around 50\% to $80 \%$ of the cycle, respectively. ${ }^{20}$ The curve aspect and the values obtained in the present study were similar in the conditions (with backpack and without backpack). There is a close relation of pelvic movement, which demonstrates that there is no need for further accommodation adjustments of this joint to carry out riding with backpacks with wheels. The angular displacements of the ankle, knee and pelvis seem to be less susceptible to changes induced by the transport of loads by means of wheeled backpacks in children.

Some limitations of the study as the kinetic changes between the segments would perhaps alter the kinetics or kinematics due to the load and type of backpack and trunk. In addition, it would be important to evaluate whether the children evaluated were already using dayto-day wheeled backpacks and their average load carried by these children daily, higher or lower than that used in the study. These questions emerge as ideas to be elucidated in new works.

\section{Conclusion}

The results indicate that the use of backpacks with wheels to transport loads up to $10 \%$ BW in children is an efficient resource and ensures the same conditions of movement in the plane as a result of the evaluation performed through the soil reaction forces. Thus, through the findings it is concluded that forces are dissipated directly to the ground by virtue of the arrangement of the load (inside the backpack) and the location where the backpack is (to the side/back of the body). In this sense there is no overload imposed on the locomotor system.

It is important to note that the load used (10\% in relation to body weight) may not have been enough to cause changes in the analyzed patterns. It is expected that other studies will analyze and compare the effects of load carrying by means of backpacks with wheels loads higher than those used in the present study, as well as the kinematic model may include all or most segments related to the upper limbs, in order to guarantee this condition to the persons who need the use of this means for the transport of loads. 


\section{References}

1. Sedrez JA, Da Rosa MIZ, Noll M, da Silva Medeiros F, Candotti CT. Fatores de risco associados a alterações posturais estruturais da coluna vertebral em crianças e adolescentes. Rev Paul Pediatr. 2015;33(1), 72-81.

2. Pranata A, Perraton L, El-Ansary D, Clark R, Mentiplay B, Fortin K, Bryant AL. Trunk and lower limb coordination during lifting in people with and without chronic low back pain. J Biomech. 2018;71, 257-263.

3. Adler NS, Csongradi J, Bleck EE. School Screening for scoliosis. W J Med. 1984; 141: 631-3.

4. Kasser SL, Jacobs J V. Understanding and treating balance impairment in multiple sclerosis. JCOM, 2014; 21(9), 419-32.

5. Souza Melo R, da Silva PWA, Macky CFDST, Silva LVC. Análise postural da coluna vertebral: estudo comparativo entre surdos e ouvintes em idade escolar. Fisioter Mov. 2017; 25(4): 803-810.

6. Dahl KD, Wang H, Popp JK, Dickin DC. Load distribution and postural changes in young adults when wearing a traditional backpack versus the BackTpack. Gait Posture, 2016;45, 90-96.

7. Li SS, Chow DH. Effects of backpack load on critical changes of trunk muscle activation and lumbar spine loading during walking. Ergonomics, 2018;61(4): 553-565.

8. Castillo ER, Lieberman DE. Shock attenuation in the human lumbar spine during walking and running. J Exp Biol. 2018; jeb-177949.

9. Yamato TP. Do schoolbags cause back pain in children and adolescents? A systematic review. Br J Sports Med. 2018; 52:1241-1245.

10. Carvalho LAP, Rodacki ALF. The influence of two backpack loads on children's spinal kinematics. Rev bras Educ Fís Esp. 2008;22(1):45-52.
11. Quixadá, A. P., Ramalho, P., Baptista, A. F., Mendes, S. M. D., Aragão, J. H., \& Sá, K. N. (2015). Alterações posturais associadas ao uso de mochilas em escolares. Rev Pesq Fisioter. 2015;1(1):91-99.

12. Delgado RDCM, Berto R. Distribuição da força plantar em relação ao peso e posicionamento do material escolar. Rev Eletr Educ Cien. 2015;5(1), 25-32.

13. Needham R, Stebbins J, Chockalingam N. Threedimensional kinematics of the lumbar spine during gait using marker-based systems: a systematic review. J Med Eng Technol. 2016;40(4):172-185.

14. Zambaldi PA, da Costa TABN, Diniz GDCLM, Scalzo PL. Efeito de um treinamento de equilíbrio em um grupo de mulheres idosas da comunidade: estudo piloto de uma abordagem específica, não sistematizada e breve. Acta Fisiatrica. 2016;14(1): 17-24.

15. Estrázulas JA, Pires R, Santos DM, Stolt LROG, Melo SIL. Características biomecânicas da marcha em crianças, adultos e idosos. Lecturas Educación Física e Deportes, Revista Digital, Buenos Aires, 2005; 2005:1-7.

16. Orantes-Gonzalez E, Heredia-Jimenez J, Beneck GJ. Children require less gait kinematic adaptation to pull a trolley than carry a backpack. Gait Posture. 2017; 52:189-93.

17. Hong $Y$, Jing $X$. Influence of load and carrying methods on gait phase and ground reactions in children`s stair walking. Gait Posture. 2005;22(2):63-68.

18. Himmann JE, Cunbigham DA, Rechnitzer PA, Paterson DA. Age-related changes in speed of walking. Med Sci Sports Exerc. 1988;20(2):161-166.

19. Mann L, Teixeira CS, Mota CB. A marcha humana: interferências de cargas e de diferentes situações. Arq Cienc Saúde Unipar. 2008;12(3):257-264.

20. Butler EE, Steele KM, Torburn L, Gamble JG, Rose J. Clinical motion analyses over eight consecutive years in a child with crouch gait: a case report. J Med Case Rep, 2016;10(1), 157. 